\title{
An improved method for estimating water-mass ventilation age from radiocarbon data
}

\author{
Tim DeVries* , François Primeau \\ Department of Earth System Science, University of California, Irvine, CA 92697, United States
}

\section{A R T I C L E I N F O}

\section{Article history:}

Received 22 October 2009

Received in revised form 3 April 2010

Accepted 8 April 2010

Available online 20 May 2010

Editor: M.L. Delaney

\section{Keywords:}

Ocean Drilling Program

Site 887

ventilation age

radiocarbon

transit-time distribution

glacial-interglacial

\begin{abstract}
A B S T R A C T
Existing methods for inferring the ventilation age of water masses in the ocean using radiocarbon data neglect the effects of diffusive mixing. In the presence of varying atmospheric $\Delta^{14} C$, this neglect produces spurious time dependence in the estimated ventilation ages. To correct this deficiency we propose a new method for estimating the ventilation age from sediment core radiocarbon data. The new method is formulated in terms of parameterized age distributions that account for the effects of advective and diffusive transport in the ocean. When applied to simulated radiocarbon data from an OGCM, the method is able to closely reproduce the modeled ventilation age, whereas other methods are not. We also applied the method to sediment-core radiocarbon data from the deep subarctic northeast Pacific. We estimated the model parameters using a Bayesian approach that allows for a careful quantification of the uncertainty in the inferred ventilation age. Results from the sediment-core analysis show larger ventilation ages during the last glacial maximum compared to the Holocene, although uncertainty on individual age estimates is high. Large excursions in ventilation ages for one of the cores may also indicate a change in the reservoir age of North Pacific surface waters during the last deglaciation.
\end{abstract}

(c) 2010 Elsevier B.V. All rights reserved.

\section{Introduction}

The ventilation age of a water mass is defined as the time that has elapsed since the water was last at the sea surface (e.g. Thiele and Sarmiento, 1990). The concept of ventilation age is used extensively in oceanography - for example in estimating the rate of ventilation (Hall et al., 2007), the rate of oxygen utilization (Feely et al., 2004), and the rate at which the ocean takes up anthropogenic $\mathrm{CO}_{2}$ (Hall et al., 2002; Waugh et al., 2006; Khatiwala et al., 2009). Ventilation age records estimated from deep-sea sediment cores (Sikes et al., 2000; Broecker et al., 2004; Robinson et al., 2005; Galbraith et al., 2007; Broecker et al., 2008) provide key constraints on the ability of the deep-ocean reservoir to accumulate a sufficient amount of respired $\mathrm{CO}_{2}$ to account for the $100 \mathrm{ppm}$ reduction in atmospheric $\mathrm{CO}_{2}$ during the last glacial maximum (e.g. Marchitto et al., 2007).

The ventilation age is particularly important for paleoceanographic applications as a measure of oceanic circulation. Ventilation ages are closely related to the ${ }^{14} \mathrm{C}$ to ${ }^{12} \mathrm{C}$ ratio recorded in foraminifera shells recovered from deep sea cores. Unlike current speeds or overturning rates, ventilation ages can be estimated without using an ocean circulation model and sophisticated data assimilation techniques. One straightforward approach approximates the ventilation

\footnotetext{
* Corresponding author.

E-mail address: tdevries@uci.edu (T. DeVries).
}

age using the difference in the radiocarbon ages of contemporaneous benthic (bottom-dwelling) and planktonic (surface-dwelling) foraminiferal shells deposited in ocean sediments. This age difference is known as the benthic-planktonic age or $B-P$ age. When corrected for an assumed surface reservoir age, the B-P age is sometimes referred to as an apparent ventilation age (e.g. Sikes et al., 2000). Adkins and Boyle, (1997) showed that the B-P age is an inaccurate estimate of the true ventilation age if the atmospheric ${ }^{14} \mathrm{C} /{ }^{12} \mathrm{C}$ ratio is not constant with time. They suggested an alternate method to account for the time dependence of the initial ${ }^{14} \mathrm{C} /{ }^{12} \mathrm{C}$ level of surface waters by extrapolating the benthic ${ }^{14} \mathrm{C} /{ }^{12} \mathrm{C}$ ratio backward to the time where it intersects the relatively well known atmospheric ${ }^{14} \mathrm{C} /{ }^{12} \mathrm{C}$ history (Adkins and Boyle, 1997). Ages produced using this method are known as projection ages. The projection age method is straightforward to apply, but makes a critical assumption that is unlikely to hold in the ocean: the water mass is transported from the surface to the deep ocean without having its initial radiocarbon signature diluted by the entrainment of older water masses with already depleted radiocarbon values. As shown in the modeling study of Franke et al. (2008b), both projection ages and B-P ages can have errors of similar magnitudes for realistic atmospheric ${ }^{14} \mathrm{C} /{ }^{12} \mathrm{C}$ histories.

An important development in the past ten years for the study of the contemporary ocean circulation using transient and radioactive tracers has been the introduction of an age distribution function, sometimes called a TTD (transit-time distribution), to take into account the fact that in the presence of mixing due to eddy-diffusion 
and shear dispersion, fluid elements are transported from the surface to the deep ocean via a multiplicity of pathways, some of which are relatively fast while others are much slower (e.g. Delhez et al., 1999; Holzer and Hall, 2000; Haine and Hall, 2002; Delhez et al., 2003; Waugh et al., 2003; Primeau, 2005; Primeau and Holzer, 2006; Peacock and Maltrud, 2006; Holzer and Primeau, 2008; Holzer et al., in press). In this paper we present an improved method for estimating paleo-ventilation ages from radiocarbon data that makes use of the age distribution concept. Our new method is based on an integral equation that relates the deep-water ${ }^{14} \mathrm{C} /{ }^{12} \mathrm{C}$ concentrations to the atmospheric radiocarbon history using parametric functions that represent the distribution of times since water parcels in the deep ocean were last equilibrated with the atmosphere. For radiocarbon, the age distribution can be factored into two parts, one that is associated specifically with the air-sea equilibration of ${ }^{14} \mathrm{CO}_{2}$ and a second part that is associated with tracer-independent transport processes. To estimate the parameters in our model, we use a Bayesian methodology that allows a careful determination of the most probable values of the parameters and their uncertainty. We illustrate the use of the new model and estimation method by first applying it to simulated radiocarbon data from an OGCM, and then by applying it to radiocarbon data from two sediment cores in the deep subarctic northeast Pacific (Galbraith et al., 2007; Gebhardt et al., 2008).

\section{Integral equations for oceanic radiocarbon}

The radiocarbon content $R$ of dissolved inorganic carbon (DIC) in the ocean, expressed as the ratio ${ }^{14} \mathrm{C} /{ }^{12} \mathrm{C}$ relative to some arbitrary standard ratio, can be treated to a good approximation as a passive tracer governed by the advection-diffusion equation,

$\frac{\partial}{\partial t} R+\nabla \cdot[\mathbf{u}-\mathbf{K} \cdot \nabla] R=-\lambda R$,

where $\mathbf{u}$ is the fluid velocity, $\mathbf{K}$ is the eddy-diffusivity tensor, $\nabla$ is the gradient operator, and $\lambda^{-1}=8266$ years is the e-folding decay timescale for ${ }^{14} \mathrm{C}$ (Toggweiler et al., 1989). Biological sources and sinks of $R$ are generally neglected because their influence is small (Fiadeiro, 1982). Eq. (1) is solved subject to a surface boundary condition that prescribes the air-sea flux,

$F=k\left(R_{a t m}-R\right)$

where $k$ is the gas exchange piston velocity for $R$ and $R_{a t m}$ is the radiocarbon content of atmospheric $\mathrm{CO}_{2}$.

The solution to Eq. (1) at any time $t$ and any point $\mathbf{r}$ in the interior ocean can be expressed in integral form as

$R(t, \mathbf{r})=\int_{\Omega} \int_{-\infty}^{t} e^{-\lambda \tau} \mathcal{G}\left(t, \mathbf{r} \mid \mathbf{r}_{s}, t-\tau\right) R_{\text {surf }}\left(t-\tau, \mathbf{r}_{s}\right) d \tau d \mathbf{r}_{s}$,

where

$R_{\text {surf }}\left(t-\tau, \mathbf{r}_{s}\right)=\int_{-\infty}^{t} e^{-\lambda \tau_{e}} \mathcal{K}\left(t-\tau, \mathbf{r}_{s} \mid t-\tau_{e}-\tau\right) R_{a t m}\left(t-\tau-\tau_{e}\right) d \tau_{e}$

The first equation propagates the surface radiocarbon concentration history, $R_{\text {surf }}$, into the interior radiocarbon distribution, $R$. The Green function kernel, $\mathcal{G}\left(t, \mathbf{r} \mid \mathbf{r}_{s}, t-\tau\right)$, partitions the water parcel in the interior ocean at $\mathbf{r}$ according to where $\left(\mathbf{r}_{s}\right)$ and when $(t-\tau)$ its fluid elements were last in the surface mixed layer. The time lag $\tau$ is the surface-to-interior transit time, and the exponential term, $e^{-\lambda \tau}$, accounts for the radioactive decay en route from the sea surface. The second equation propagates the atmospheric ${ }^{14} \mathrm{C}$ history, $R_{\text {atm }}$, into $R_{\text {surf. }}$ The integration kernel, $\mathcal{K}\left(t-\tau, \mathbf{r}_{s} \mid t-\tau_{e}-\tau\right)$, partitions the water at $\mathbf{r}_{s}$ according to when $\left(t-\tau-\tau_{e}\right)$ it was last in equilibrium with the atmospheric radiocarbon. The time lag $\tau_{e}$ is due to the slow air-sea equilibration time for ${ }^{14} \mathrm{C}$ that allows older waters to be entrained into the surface mixed layer without immediately equilibrating with the atmosphere. The exponential term, $e^{-\lambda \tau_{e}}$, accounts for the decay of radiocarbon since the fluid elements were last equilibrated with the atmospheric ${ }^{14} \mathrm{CO}_{2}$. Importantly, $\mathcal{G}$ and $\mathcal{K}$ are both distribution functions. Some atoms arrive at $\mathbf{r}$ relatively quickly while others take eddy-driven "random walks" from the atmosphere to $\mathbf{r}$ leading to $\mathcal{K}$ and $\mathcal{G}$ that are broad distributions in terms of $\tau_{e}$ and $\tau$. The ${ }^{14} \mathrm{C} /{ }^{12} \mathrm{C}$ concentration at $(t, \mathbf{r})$ is therefore obtained by integrating over all possible surface points $\mathbf{r}_{s}$, equilibration times $\tau_{e}$, and surface-tointerior transit times $\tau$.

To focus on the distribution of transit times, we will make the simplifying assumption that the water mass at location $\mathbf{r}$ is ventilated from a sufficiently small source region that the $\mathbf{r}_{s}$ dependence in Eqs. (3) and (4) can be ignored. This simplifying assumption greatly reduces the number of degrees of freedom in the problem, but will not be valid for all deep water masses. In this paper we will restrict our analysis to data obtained from the deep subarctic northeast Pacific. Inversions of modern tracer data suggest that about $80 \%$ of the bottom waters in this region are ventilated from the Southern Ocean (Gebbie and Huybers, in press), a sufficiently large number to render the single source region assumption tolerable.

When there is no $\mathbf{r}_{s}$ dependence, the integration kernel $\mathcal{G}(t, \mathbf{r} \mid t-\tau)$ is sometimes referred to as the transit-time distribution or TTD (Holzer and Hall, 2000; Haine and Hall, 2002; Peacock and Maltrud, 2006), where $\tau$ represents the surface-to-interior transit time, also known as the ventilation age. The integration kernel $\mathcal{K}\left(t-\tau \mid t-\tau-\tau_{e}\right)$ has been referred to as a boundary condition kernel by Haine (2006). In this work, we will refer to $\mathcal{K}\left(t-\tau \mid t-\tau-\tau_{e}\right)$ as the equilibration-time distribution or ETD, to stress the physical interpretation of $\tau_{e}$ as the time elapsed since a water particle in surface waters was last in equilibrium with the atmospheric ${ }^{14} \mathrm{C} /{ }^{12} \mathrm{C}$ ratio.

If the flow field, $\mathbf{u}$, and eddy-diffusivity tensor $\mathbf{K}$ for the ocean are known, the integration kernels $\mathcal{G}(t, \mathbf{r} \mid t-\tau)$ and $\mathcal{K}\left(t-\tau \mid t-\tau-\tau_{e}\right)$ can be obtained by solving Eq. (1) subject to appropriate surface boundary conditions as detailed in Appendix A. To demonstrate this, we computed both $\mathcal{G}$ and $\mathcal{K}$ using an ocean general circulation model. The OGCM used here has a steady time-averaged circulation as described in Primeau (2005). The gas transfer velocity for radiocarbon was calculated according to Eq. (B.7) in Appendix B. We used an atmospheric $\mathrm{pCO}_{2}$ of $280 \mathrm{ppm}$ and an air-sea piston velocity from the OCMIP-2 protocol (http://www.ipsl.jussieu.fr/OCMIP/phase2/ simulations), reduced by $20 \%$ to account for the recent estimates of Sweeney et al. (2007).

The red curves in Fig. 1 show examples of the TTD $(\mathcal{G})$ and ETD $(\mathcal{K})$ from the model output. The colored circles mark the locations of the displayed TTDs, and coincide with the locations of published sediment-core radiocarbon records from the deep North Pacific. The yellow circle marks the location of the sediment cores analyzed in this paper. The colored stars mark the locations of the displayed ETDs, coinciding with the surface waters above the North Pacific core site, the southern ocean surface waters which ventilate the North Pacific, and for comparison the surface waters in the North Atlantic deep-water formation region. Printed on each subplot is the mean $\theta$ of the distribution as well as a scale parameter $\beta$ which is equal to the ratio of the variance to the mean of the distribution. Fig. 2 shows spatial patterns of $\Theta$ and $\beta$, calculated from the OGCM results, for the TTD at $3800 \mathrm{~m}$ and for the ETD (which is only defined at the surface).

Fig. 1 clearly shows that both $\mathcal{G}$ and $\mathcal{K}$ are broad distributions rather than single sharp peaks. The model based TTD is characterized by a wide spectrum of ventilation ages indicating that water parcels travel from the surface to the interior along a multiplicity of ventilation pathways. Another important feature of the TTD is that 

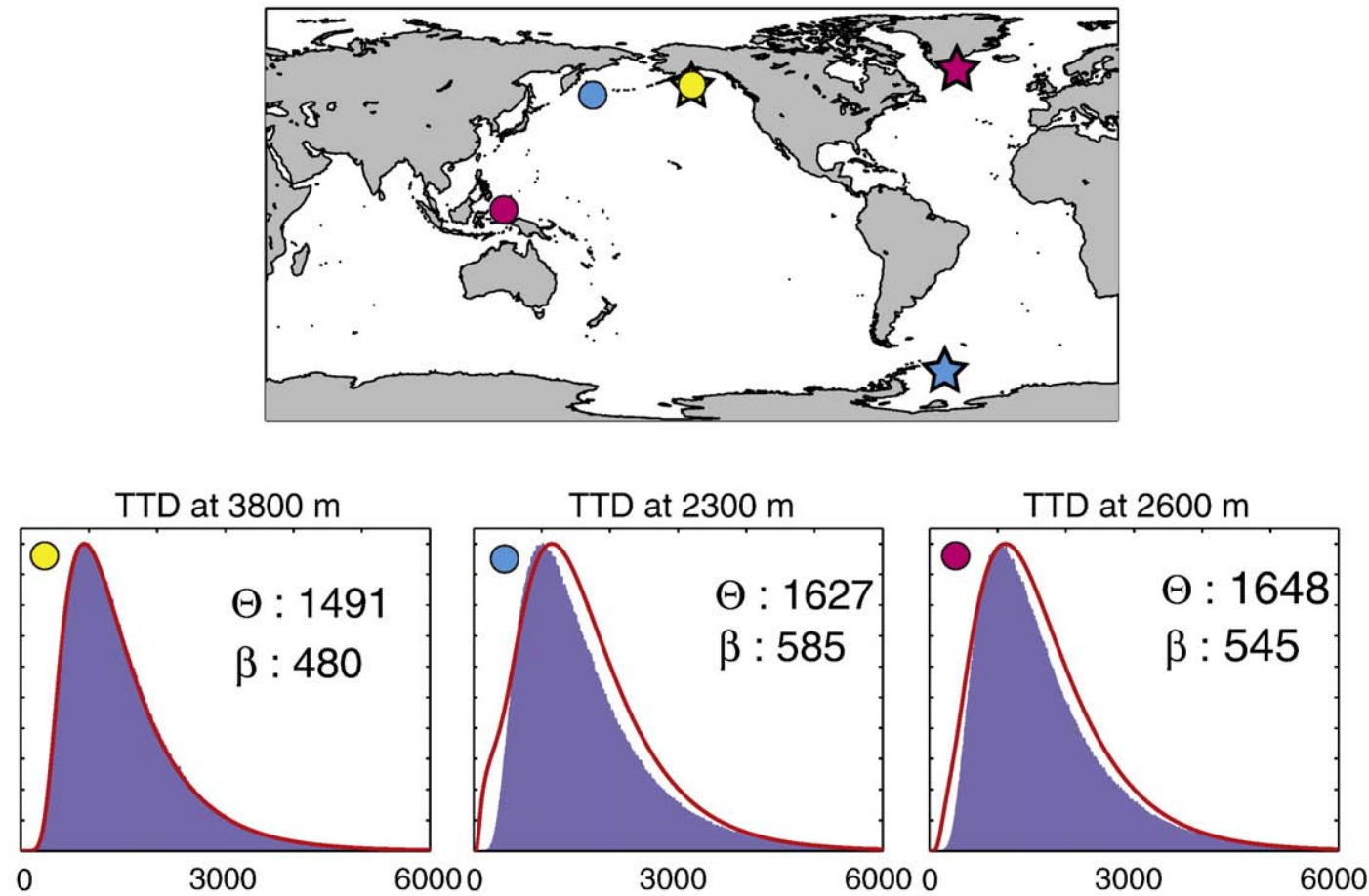

ETD

ETD

ETD
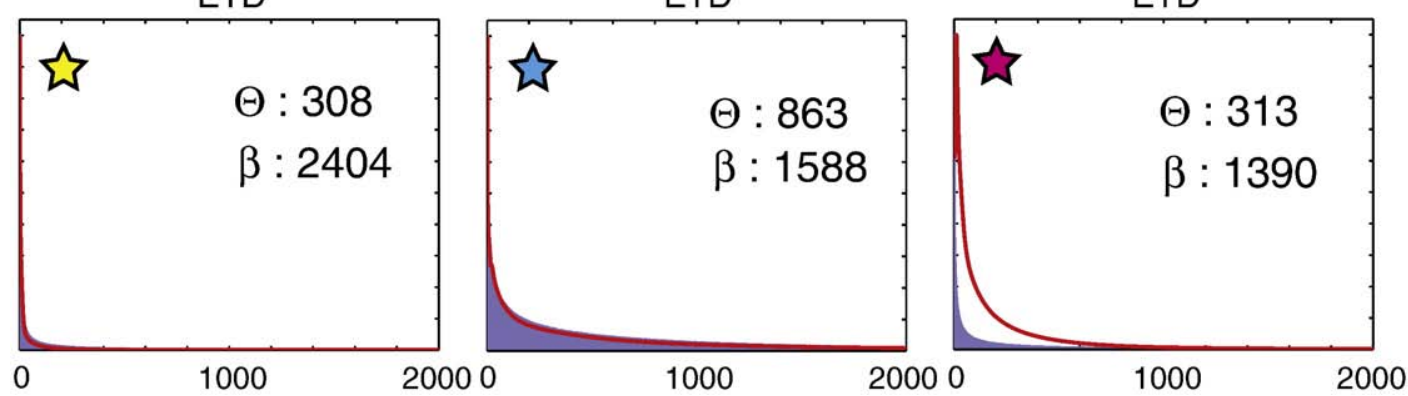

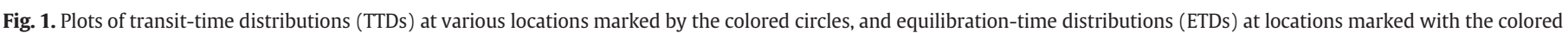

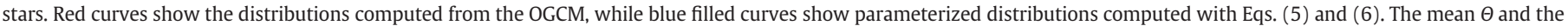
scale parameter $\beta$ (the ratio of the variance to the mean) of each distribution are printed on each plot. The $x$-axis marks the age in years.

the width increases along with its mean value, reflecting the fact that older water masses have had more time to mix. This is clear from Fig. 2 which shows that the mean of the TTD increases from south-to-north in the Pacific Ocean, but that $\beta$ remains relatively constant along the same transect.

Like the TTD, the broad shape of the ETD is also largely the result of mixing processes in the ocean. The rapid initial decrease in the ETDs seen in Fig. 1 is consistent with an $e$-folding air-sea equilibration timescale for ${ }^{14} \mathrm{CO}_{2}$ of about 5-10 years (Rodgers et al., 2000), and the relatively rapid exchange of water between the mixed layer and the upper thermocline. The long tail of $\mathcal{K}$ on the other hand is indicative of the exchange of water with the more slowly ventilated parts of the deep ocean. Fig. 2 shows that the mean of the ETD is largest in the upwelling zones in the Southern Ocean and eastern equatorial Pacific, where old waters are exposed at the surface. The mean of the ETD is closely related to the radiocarbon reservoir age of surface waters large values of the mean of the ETD correspond to old reservoir ages. However, the reservoir age depends on the time history of the atmospheric $\Delta^{14} \mathrm{C}$, as shown by Franke et al. (2008a), whereas the mean of the ETD does not. The reservoir age can be younger (older) than the mean of the ETD if atmospheric $\Delta^{14} \mathrm{C}$ is decreasing (increasing) with time, since the tail of the ETD extends thousands of years into the past.

\subsection{Parameterized forms of the integral equations}

The key advantage of using the integral Eqs. (3) and (4) instead of the differential Eq. (1) is that $\mathcal{G}$ and $\mathcal{K}$ are more amenable to being parametrized than $\mathbf{u}$ and $\mathbf{K}$. Following others we adopt the inverse Gaussian (IG) distribution to parametrize $\mathcal{G}$. The IG distribution provides a good approximation to TTDs computed from ocean circulation models, especially if the TTDs are used for propagating tracers with millennial timescales such as radiocarbon (Peacock and Maltrud, 2006). The IG parametric form has also been used as a parametrized form of the TTD to infer the amount of anthropogenic $\mathrm{CO}_{2}$ in the ocean (Hall et al., 2002, 2004; Waugh et al., 2006). Additionally, the IG distribution is the solution to the one-dimensional advection-diffusion equation, so that the use of the IG form has some physical basis. The functional form of the IG distribution with mean $\Theta$ and scale parameter $\beta$, is

$\mathcal{G}(t, \mathbf{r} \mid t-\tau)=\frac{\Theta}{\sqrt{2 \pi \beta^{2} \tau^{3}}} \exp \left[\frac{-(\tau-\Theta)^{2}}{2 \beta \tau}\right]$.

We have left out the dependence of $\Theta$ and $\beta$ on $\mathbf{r}$ and $t$ to avoid notational clutter. The filled blue curves in Fig. 1 show IG distributions with the same mean and variance as the model-based TTDs, showing 

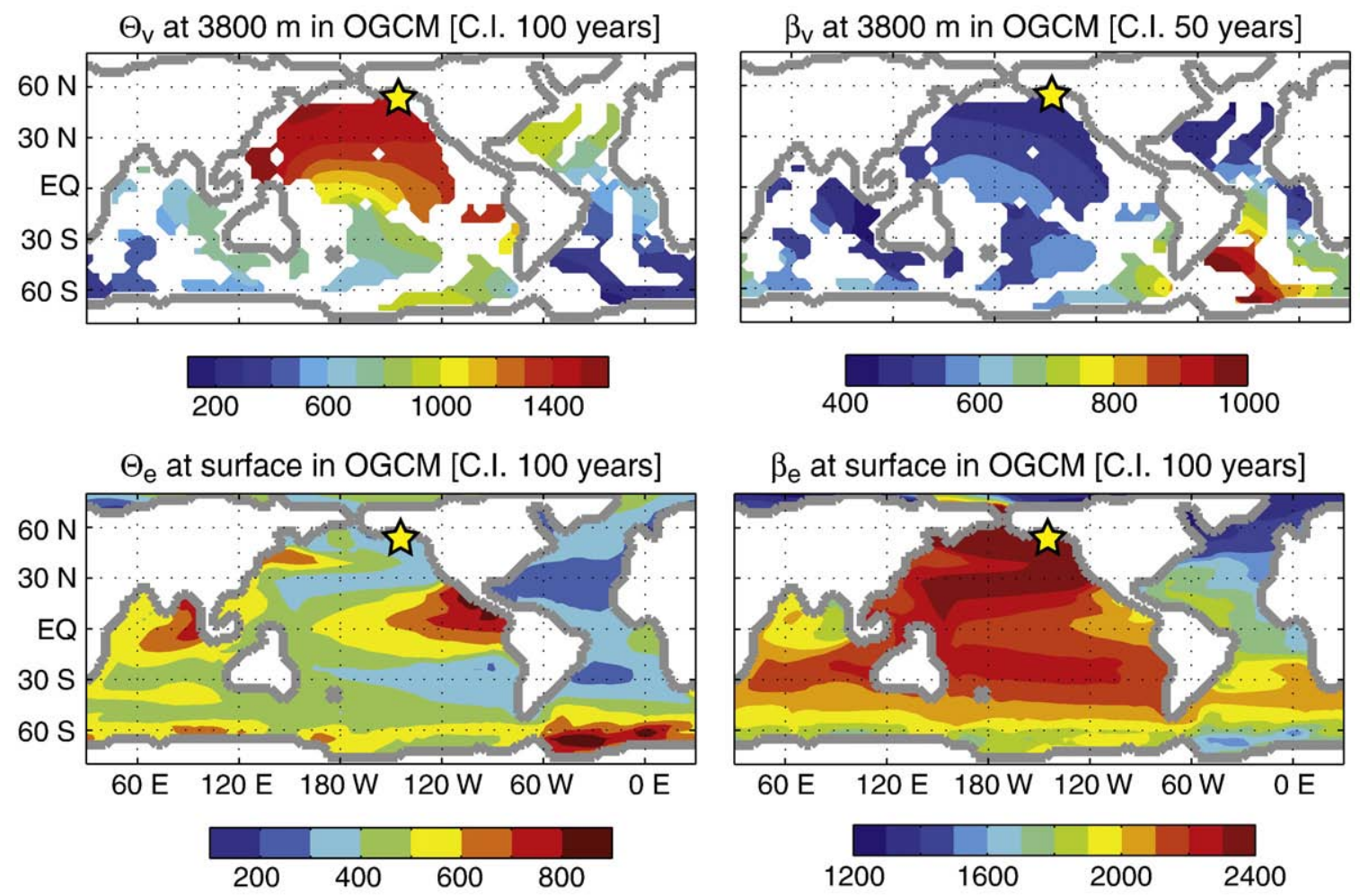

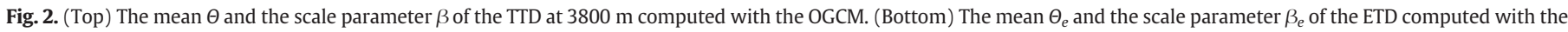
OGCM. The yellow star in the North Pacific marks the location of the cores ODP 887 and MD02-2489.

the good agreement between the model calculations and the parametric form in the North Pacific.

Haine (2006) presented analytic solutions for the boundary condition kernel $\mathcal{K}$ for several physical flows, including the onedimensional advection-diffusion equation. However, even for this simplest case the solutions do not admit closed-form solutions for the mean and width of the distribution. For this reason, we have chosen to parameterize the ETD with a gamma distribution, which also provides a good fit to the model-calculated ETDs. The functional form of the gamma distribution with mean $\Theta_{e}$ and scale parameter $\beta_{e}$, is

$\mathcal{K}\left(t-\tau \mid t-\tau-\tau_{e}\right)=\tau_{e}^{\Theta_{e} / \beta_{e}-1} \beta_{e}^{-\Theta_{e} / \beta_{e}}\left[\Gamma\left(\frac{\Theta_{e}}{\beta_{e}}\right)\right]^{-1} \exp \left(\frac{\tau_{e}}{\beta_{e}}\right)$,

where $\Gamma$ is the Gamma function. Again, to avoid notational clutter we have left out the $t-\tau$ dependencies of $\Theta_{e}$ and $\beta_{e}$. The filled blue curves in the ETD panels in Fig. 1 show gamma distributions with the same mean and variance as the model-based ETDs - again a relatively good agreement between the model calculations and the parametric form is obtained.

To further check if the gamma distribution provides a suitable fit to the ETD for radiocarbon, we calculated the surface ocean radiocarbon concentration at several times $t$ using Eq. (4) with the OGCM-based $\mathcal{K}$, and then with the $\mathcal{K}$ replaced by the parameterized gamma distribution ETD. The atmospheric radiocarbon history $R_{a t m}$ is from IntCal09 (Reimer et al., 2009). The results showed that the surface ocean radiocarbon age calculated with the parameterized ETD was usually within 10-20 years of that calculated with the OGCM-based ETD. The maximum discrepancy occurred at $t=0$ (i.e. 1950) in the North Atlantic where the difference between the two reached 50 years. Therefore, the gamma distribution provides a suitable fit to the ETD for radiocarbon.

\section{Application of the TTD-ETD method to simulated data}

To check if using the parameterized TTDs and ETDs can actually yield improved estimates of ventilation age, we performed a test using simulated data from a transient run of the OGCM. In the transient run, the ocean circulation and the air-sea gas exchange rate are constant through time, but the atmosphere radiocarbon ratio $R_{a t m}$ varies with time according to the IntCal09 reconstruction (Reimer et al., 2009). The model is initialized in steady-state with $R_{a t m}$ at $40 \mathrm{ka}$, and results from the last $24 \mathrm{ka}$ of the simulation are plotted in Fig. 3.

Fig. 3 shows the atmospheric radiocarbon history $R_{a t m}$, as well as the surface ocean and deep ocean radiocarbon concentrations for the location marked by the yellow star and circle in Fig. 1. Here the radiocarbon concentration is expressed in $\Delta^{14} \mathrm{C}$ notation. For comparison, triangles at $0 \mathrm{ka}$ mark the pre-bomb surface and deep-ocean radiocarbon concentrations from the GLODAP data set (Key et al., 2004). The model agrees almost exactly with the data in the deep ocean, but has a higher radiocarbon concentration in the surface ocean. However, the GLODAP surface ocean data value is subject to much more uncertainty than the deep ocean data value due to contamination by bomb ${ }^{14} \mathrm{C}$. Overall, the rms misfit between the model and the data in the deep ocean (below $2000 \mathrm{~m}$ ), excluding the Arctic Ocean, is 27\%.

From the simulated data, we calculated the ventilation age in four ways, as shown in the bottom panel of Fig. 3. The "true" mean age (black line) is the mean of the ventilation age distribution in the deep North Pacific, and is a constant 1491 years throughout the simulation, reflecting the steady circulation. The B-P age (magenta curve) was calculated from the difference between the modeled surface and deep radiocarbon ages in the North Pacific, while the projection age (blue curve) was calculated by projecting back to the atmospheric curve and correcting for an assumed source-region reservoir age of 700 years, reflecting a Southern Ocean source region. Both the B-P ages and the projection ages show large and conflicting fluctuations. 

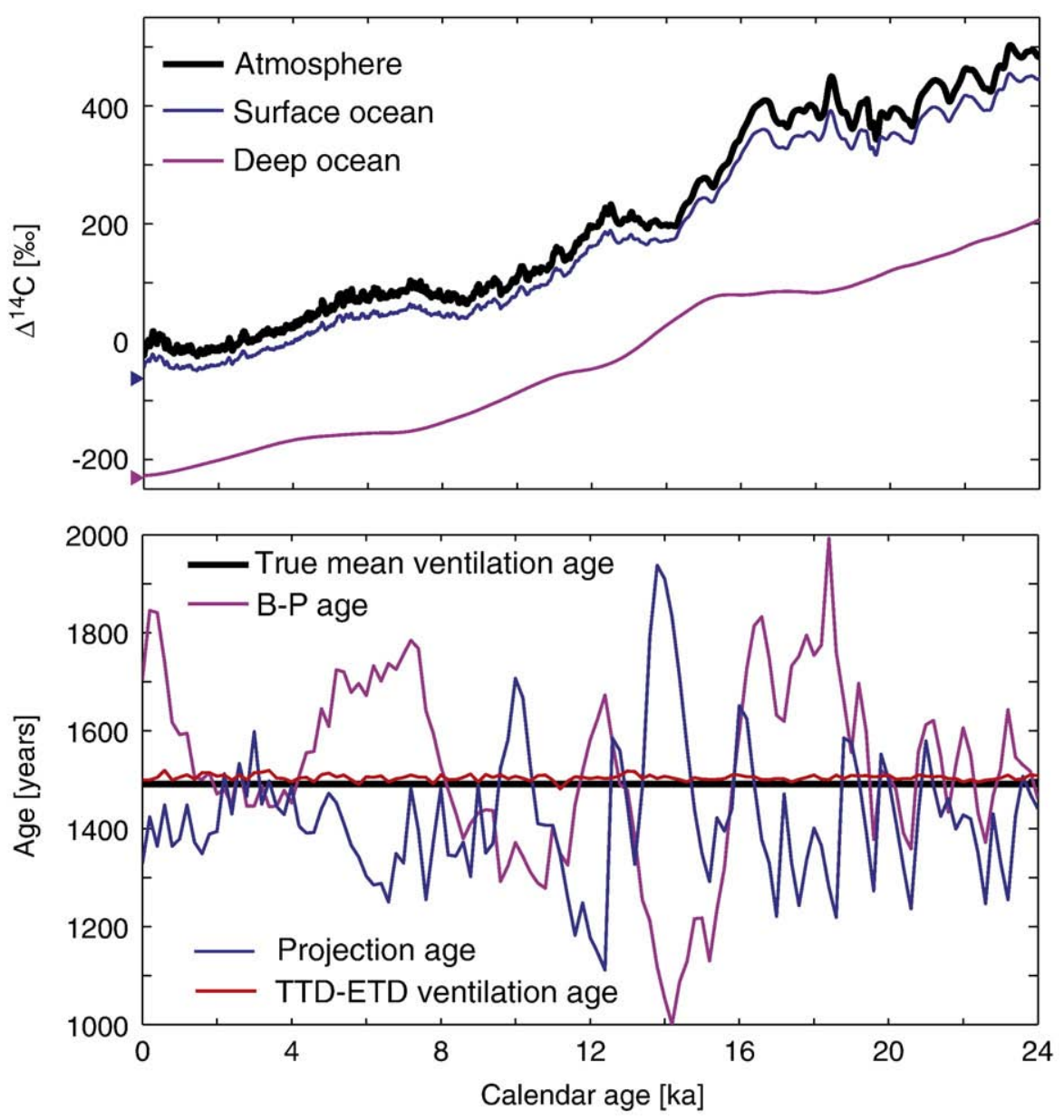

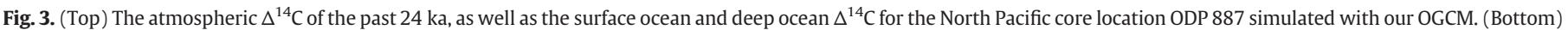

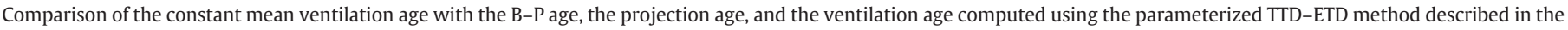
text.

Disconcertingly, some of the implied changes in ocean circulation can appear quite abrupt with implied changes in the ventilation ages of a few hundred years happening in a few hundred calendar years.

We also computed the ventilation age using the parameterized TTD-ETD method (red curve). For this calculation, we assumed a value of 480 years for the scale parameter $\beta$ for the TTD, the value calculated from the OGCM-derived TTD. For the ETD, we assumed a mean $\theta_{e}$ of 700 years and scale parameter $\beta_{e}$ of 1700 years, reflecting the mean values of these parameters in the Southern Ocean from the OGCM-derived ETDs. We then inferred the mean of the TTD by solving Eqs. (3) and (4) iteratively, using the parameterized TTD and ETD in place of $\mathcal{G}$ and $\mathcal{K}$, to find the value that best fit the simulated data. The inferred ventilation age is very close to the true mean age throughout the simulation, and shows little variability, unlike the B-P or projection ages. The (small) difference between the "true" mean ventilation age (black line) and the inferred ventilation age (red curve) is due to the assumption of a single source region and misfit between the model-derived and parameterized TTD and ETD. The significant improvement over the B-P age or projection age estimates argues persuasively for adopting the TTD-ETD method.

To check how sensitive the ventilation age inferred using the TTDETD method is to the width of the TTD and ETD, we repeated the calculations described above for TTDs and ETDs with the scale parameter $\beta$ ranging from near 0 to 1.5 times the values calculated from the OGCM. Fig. 4a-b shows the TTD and ETD for each of the different values of $\beta$ used. A $\beta$ value of 0 is in no way realistic, but is included to show how the projection method is a special case of the TTD-ETD method with zero-width age "distributions" (i.e. delta functions). As shown in Fig. 4c, the ventilation ages in the case $\beta$ and $\beta_{e} \rightarrow 0$ are equal to the projection ages. As the width of the age distribution is widened by increasing the value of $\beta$, spurious fluctuations in the ventilation age are smoothed out, until the optimal width is reached (solid blue curve). If $\beta$ is allowed to get too large, spurious age fluctuations are again encountered. However, for values of $\beta$ from 0.5 to 1.5 times the values of $\beta$ estimated from the OGCM, the inferred ventilation age is always within 100 years of the true mean age. This indicates that the TTD-ETD method is relatively insensitive to the width of the age distributions, as long as the width is not allowed to approach zero.

\section{Application of the TTD-ETD method to sediment core data}

To demonstrate the application of the TTD-ETD method to sediment-core data, we apply the method to analyze radiocarbon data from two sediment cores in the deep subarctic northeast Pacific: ODP $887\left(54.37^{\circ} \mathrm{N}, 148.45^{\circ} \mathrm{W}, 3647 \mathrm{~m}\right)$ (Galbraith et al., 2007) and MD02-2489 (54.39 N, $148.92^{\circ} \mathrm{W}, 3640 \mathrm{~m}$ ) (Gebhardt et al., 2008).

\subsection{Sediment core data and TTD-ETD simulations}

The sediment core radiocarbon data is presented as paired benthic and planktonic radiocarbon ages $\left(t_{R}^{p}, t_{R}^{b}\right)$, along with their uncertainty $\left(\sigma_{t_{R}^{p}}, \sigma_{t_{R}^{b}}\right)$, for various depths in the sediment core. For depths where duplicate measurements were available we used the average. For depths where there were benthic radiocarbon ages but no planktonic radiocarbon ages (MD02-2489 only) we extrapolated the planktonic 
TTD

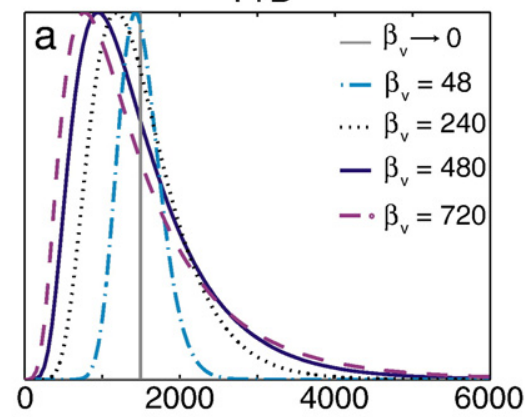

ETD

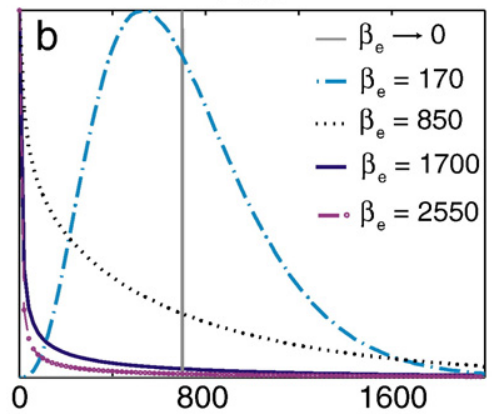

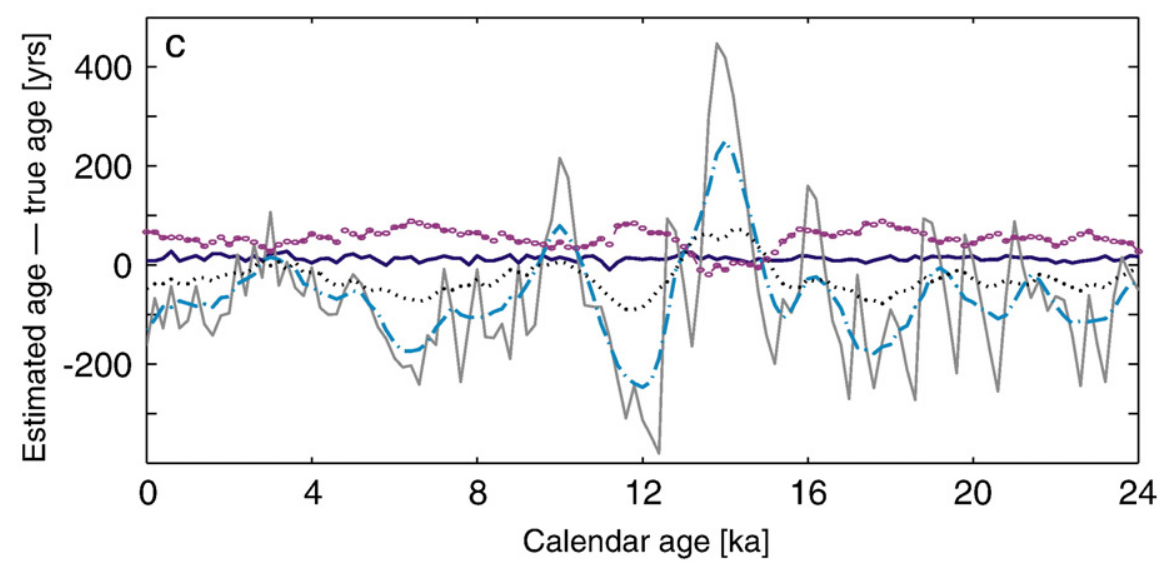

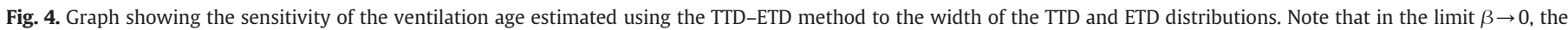
ventilation age inferred using the TTD-ETD is equal to the projection age.

ages linearly, and used the uncertainty from the nearest neighbor with the largest uncertainty.

The TTD-ETD method is applied to simulate the planktonic and benthic radiocarbon ages at each depth in the sediment core. The simulated planktonic radiocarbon age is computed by first calculating the local surface ocean radiocarbon ratio $R_{\text {surf }}$ using Eq. (3). The integration kernel $\mathcal{K}$ (the ETD) is parameterized, as in Eq. (6), with a mean $\Theta_{e}^{l}$ and scale parameter $\beta_{e}^{l}$. Here the $l$ superscript indicates local surface ocean values. The surface ocean radiocarbon age $t_{R}^{\text {surf }}$ is then found using the transformation

$t_{R}^{\text {surf }}\left(\Theta_{e}^{l}, \beta_{e}^{l}, t\right)=\frac{\lambda t-\ln \left(R_{\text {surf }}\left(\Theta_{e}^{l}, \beta_{e}^{l}, t\right)\right)}{\lambda_{L}}$.

where $\lambda_{L}=8033$ years is the Libby radiocarbon decay timescale. The deep ocean, or benthic, radiocarbon age is computed using a similar procedure except that we use different parameters, $\Theta_{e}^{s}$ and $\beta_{e}^{s}$, for the ETD to reflect the fact that the source waters ventilating the deep ocean do not have the same equilibration time distribution as the local surface waters. Here the $s$ superscript indicates the surface source region. We then use Eq. (4), with the integration kernel $\mathcal{G}$ (the TTD) parameterized as in Eq. (5) with a mean $\Theta$ and scale parameter $\beta$, to compute the deep ocean radiocarbon ratio $R$. The deep ocean radiocarbon age $t_{R}$ is then found using the transformation

$t_{R}\left(\Theta_{e}^{s}, \beta_{e}^{s}, \Theta, \beta, t\right)=\frac{\lambda t-\ln \left(R\left(\Theta_{e}^{s}, \beta_{e}^{s}, \Theta, \beta, t\right)\right)}{\lambda_{L}}$.

\subsection{Atmospheric radiocarbon data}

In all our calculations, we used the atmospheric radiocarbon history from the INTCAL09 reconstruction, which is the consensus radiocarbon calibration curve for the time period 0 to $50 \mathrm{ka}$ (Reimer et al., 2009). Since we found that the uncertainty in the atmospheric radiocarbon record is small relative to that in the sediment-core data, we have ignored uncertainty in the atmospheric radiocarbon record in the formulation of our probabilistic model (Section 4.3). The reason for the small influence of atmospheric $\Delta^{14} \mathrm{C}$ uncertainty in the TTDETD method is that the high frequency errors in the atmospheric radiocarbon history are averaged out by the finite width of the TTD and ETD. This averaging effect is absent if one uses the projection method, which is equivalent to assuming a TTD and ETD of zero width.

To illustrate this point, we calculated benthic radiocarbon ages using both the projection method and the TTD-ETD method, after adding temporally correlated noise to the atmospheric ${ }^{14} \mathrm{C}$ record. The added noise was adjusted to have roughly the same autocorrelation as the IntCal09 record, and a magnitude consistent with the uncertainty given for the IntCal09 $\Delta^{14} \mathrm{C}$. The associated uncertainty in the benthic radiocarbon age calculated with each method is shown in Fig. 5 for the time period 9-22 ka. Using the TTD-ETD method, uncertainty in the atmospheric $\Delta^{14} \mathrm{C}$ record contributes about $10-40$ years of uncertainty to the benthic radiocarbon ages. Since this is less than the uncertainty in the measured benthic radiocarbon ages, it is appropriate to ignore this source of uncertainty when estimating ventilation age with the TTD-ETD method. On the other hand, the uncertainty in the atmospheric $\Delta^{14} \mathrm{C}$ record contributes about 20-130 years of uncertainty to benthic radiocarbon ages calculated with the projection method.

\subsection{Probabilistic model}

By comparing the TTD-ETD simulated data with the sediment core data, we can constrain the parameters in our model. To do so, we adopt a Bayesian methodology which requires that we formulate a probability model, known as the likelihood, that yields the probability of the data conditional on the value of our model parameters. The 


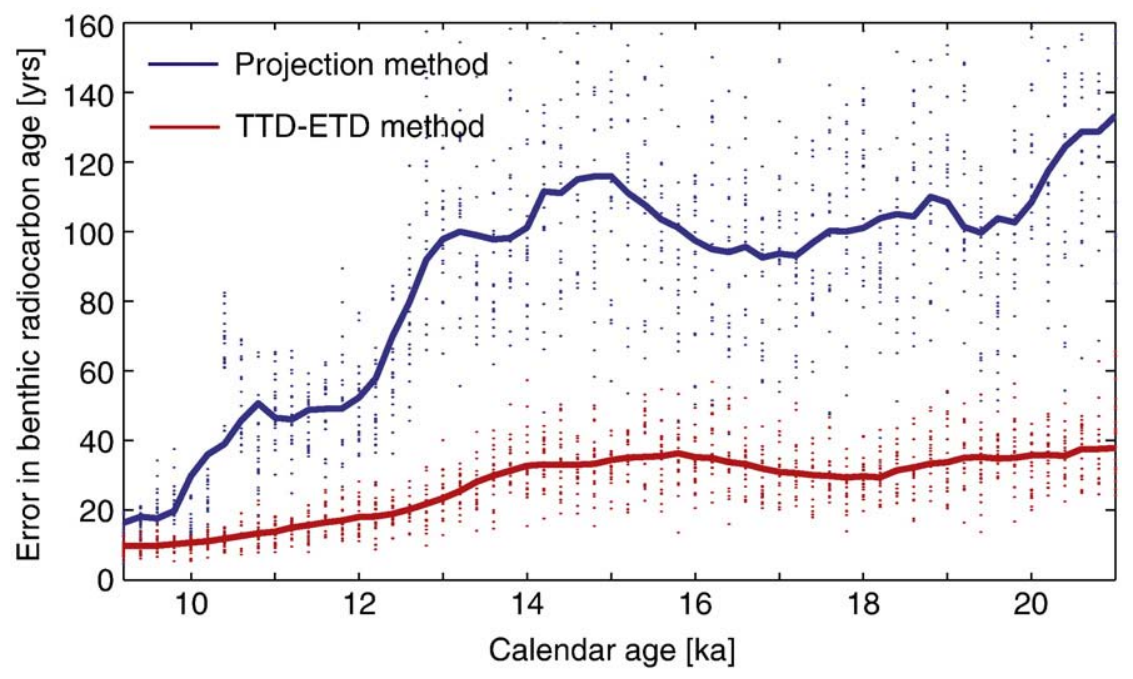

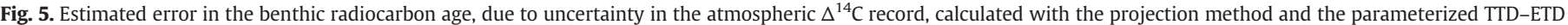
method. Dots show uncertainty estimates for 10 different calculations at 200-year intervals, while the lines show the mean uncertainty as a function of calendar age.

method also requires that we assign a prior probability density function (pdf) for our model parameters. The prior pdf is not conditioned on the data, but rather on our a priori knowledge about the most probable values of the parameters. Bayes' theorem then yields the posterior pdf for the parameters as the product of the prior and the likelihood divided by a constant normalization factor (Sivia and Skilling, 2006).

The joint probability for the data $\left\{t_{R}^{p}, t_{R}^{b}, R_{a t m}\right\}$, given the model and its parameters $\mathbf{p}=\left\{t, \Theta, \beta, \Theta_{e}^{s}, \beta_{e}^{s}, \Theta_{e}^{l}, \beta_{e}^{l}\right\}$, is modeled as the product of Gaussian distributions,

$\operatorname{prob}\left(t_{R}^{p}, t_{R}^{b}, R_{a t m} \mid \mathbf{p}\right)=\frac{1}{2 \pi \sigma_{t_{R}^{p}} \sigma_{t_{R}^{b}}} \exp \left[-\frac{\left(t_{R}^{\text {surf }}-t_{R}^{p}\right)^{2}}{2 \sigma_{t_{R}^{p}}^{2}}-\frac{\left(t_{R}-t_{R}^{b}\right)^{2}}{2 \sigma_{t_{R}^{b}}^{2}}\right]$

Eq. (9) is known as the likelihood function. The 7 parameters must be estimated using two sediment-core radiocarbon ages $\left\{t_{R}^{p}, t_{R}^{b}\right\}$, and the atmospheric radiocarbon history $R_{a t m}$. The problem is clearly under-determined and assumptions must be made about the plausible values of some of the parameters. These assumptions are encoded in the prior pdfs.

\subsection{Priors}

Prior pdfs for the calendar age, $t$, and the mean of the TTD, $\Theta$, are chosen so that there is uniform probability of any $t$ as long as it is negative (i.e. before present) and uniform probability of any $\Theta$ as long as it is positive. With uniform priors for $t$ and $\Theta$, the values of $t$ and $\Theta$ inferred by the probabilistic model will primarily reflect the information contained in the radiocarbon data. To constrain the remaining parameters, we assign non-uniform priors that are meant to capture the plausible range of each parameter.

For the mean of the local surface ETD, $\Theta_{e}^{l}$, we assign a lognormal prior with a mean of 590 years and a standard deviation of 250 years, with the peak probability occurring at about 450 years. The lognormal distribution precludes negative values and is skewed toward larger values. The estimated value of $\Theta_{e}=300$ years from our model lies below the peak probability, since we believe that the reservoir ages in our model are too low. For example, the modeling study of Butzin et al. (2005) suggests a preindustrial reservoir age of about 400 years for this region, while the GLODAP pre-bomb reservoir-age estimate is about 500 years. On the other hand, Galbraith et al. (2007) used a reservoir age correction of 950 years for this location, on the basis of estimates derived from Holocene-age fossil shells from coastal sediments (Southon et al., 1990; Kovanen and Easterbrook, 2002). While the data-based estimates are large compared to the peak of our prior pdf, we note that because the lognormal distribution is skewed, values as large as 1100 years still lie within the 95\% probability interval. Because we do not have information on how the reservoir age for this region may have changed during the deglaciation, the prior pdf for $\Theta_{e}^{l}$ is independent of the calendar age.

For the mean of the source region ETD, $\Theta_{e}^{s}$, we assign a lognormal prior pdf with a mean of 890 years and a standard deviation of 250 years, with the peak probability occurring at about 800 years. This spans the range of variability in the value of $\theta_{e}$ in the OGCMcalculated ETDs for the Southern Ocean, presumed to be the source of deep North Pacific waters. In the OGCM, the mean value of $\Theta_{e}$ in the Southern Ocean is about 600 years, but exceeds 800 years in deepwater formation zones in the Weddell Sea (c.f. Fig. 2). For comparison, model results of Butzin et al. (2005) suggest a reservoir age of about 800 years in the ice-free Southern Ocean, and the GLODAP pre-bomb reservoir age averages to 950 years over the Southern Ocean. The prior pdf for $\Theta_{e}^{s}$ is skewed toward larger values to reflect these somewhat larger estimates, and also so as not to preclude the larger Southern Ocean reservoir ages that have been hypothesized by some authors for the last deglaciation (e.g. Marchitto et al., 2007). Because we do not have information about how the Southern Ocean reservoir age may have changed during the deglaciation, the prior pdf for $\Theta_{e}^{s}$ is also independent of the calendar age.

The width-controlling scale parameters $\beta, \beta_{e}^{l}$, and $\beta_{e}^{s}$, are assigned normal (Gaussian) priors with a mean and variance determined from the OGCM-based TTDs and ETDs. The mean \pm standard deviation for the Gaussian priors are $475 \pm 50$ years for $\beta, 1600 \pm 100$ years for $\beta_{e}^{s}$, and $2400 \pm 100$ years for $\beta_{e}^{l}$. The standard deviations reflect the variance of the relevant parameters in the deep north Pacific $(\beta)$, the surface north Pacific $\left(\beta_{e}^{l}\right)$, and the Southern Ocean $\left(\beta_{e}^{s}\right)$ calculated from the OGCM.

\subsection{Numerical methods}

The integrals in Eqs. (3) and (4) were evaluated using a Monte Carlo integration method using random $\tau_{e}$ and $\tau$ samples drawn from the $\mathcal{K}$ and $\mathcal{G}$ distributions. The number of samples was chosen such that the relative error in the approximate integrals was less than $10^{-3}$, which corresponds to approximately 10 radiocarbon years.

To summarize the information in the joint posterior pdf for the parameters we used a Monte Carlo Markov Chain (MCMC) method to 
sample from the posterior. The particular MCMC method we used was the Metropolis-Hastings rule (Hastings, 1970). We ran 4 chains independently, and terminated the simulation when we determined the chains had converged to the target distribution. Convergence was diagnosed by computing and plotting the potential scale reduction factor for the 4-chain simulation (Brooks and Gelman, 1998). The results we present are based on the last $50 \%$ of the samples from each chain.

\section{Results and discussion}

Fig. 6 shows the joint posterior pdfs for the calendar age $t$, and the mean ventilation age $\theta$, for each depth in the two sediment cores. The colored cloud of points represents the posterior pdf for each depth, and each dot in the cloud of points represents one sample from the posterior pdf obtained with the MCMC sampler. Regions with dense populations of points represent regions of high probability, while regions with sparse populations of points represent regions of low probability. Error bars are shown as thick black lines that extend one standard deviation above and below the median of the posterior pdf.

The posterior probability is contained in tilted ellipses that are cut off on the side of older calendar age estimates. The cutoff corresponds to the case where the mean of the local surface ETD is zero, i.e. to the case of zero reservoir age. The exact time of the cutoff corresponds to the calendar age at which the radiocarbon decay trajectory for the measured planktonic age intersects the atmospheric radiocarbon curve. The width of the scatter (uncertainty) in the calendar age is determined primarily by uncertainty in the mean of the local surface ETD and in the measured planktonic radiocarbon age. These two sources of uncertainty also project to uncertainty in the ventilation age. In addition, uncertainty in the ventilation age is influenced by uncertainty in the mean of the source region ETD and in the measured benthic radiocarbon age. Uncertainty in the width of the TTD and ETDs contributes very little to the overall uncertainty shown in Fig. 6 .

Also shown in Fig. 6 are the B-P ages (magenta ellipses), which are plotted at the calendar ages originally inferred for ODP 887 (Galbraith et al., 2007) and MD02-2489 (Gebhardt et al., 2008). We have also plotted the projection ages, using a reservoir age correction of 900 years, as a function of calendar age for each depth. The projection ages fall along the green lines representing a radiocarbon decay trajectory. For reference, the modern ventilation age estimated with the TTD-ETD method using GLODAP radiocarbon data is indicated by the green star.

Ventilation ages inferred using the TTD-ETD method can be younger, older, or the same as the projection ages, depending on the atmospheric radiocarbon history. For the sequence in Fig. 6, ventilation ages inferred by the TTD-ETD method are typically several hundred years older than the projection ages. However, there are cases where the projection age is older than the ventilation age, as in the third depth in ODP 887 ( $\sim 14 \mathrm{ka})$, where the projection age is about 400 years too old. In general, the differences between the TTDETD ventilation ages, the B-P ages, and the projection ages are on the order of several hundred years.
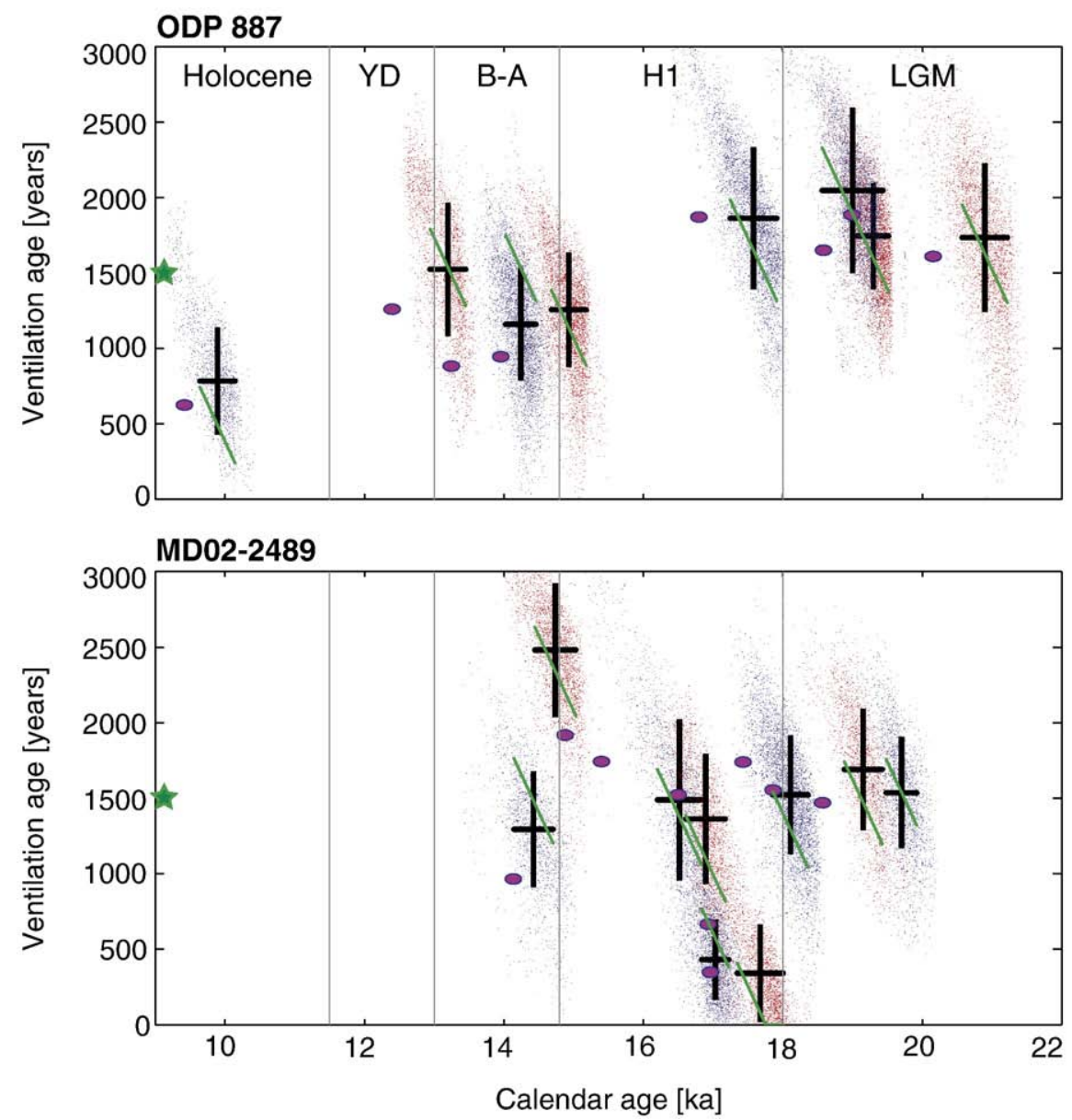

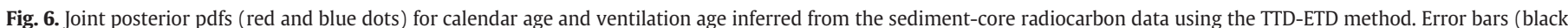

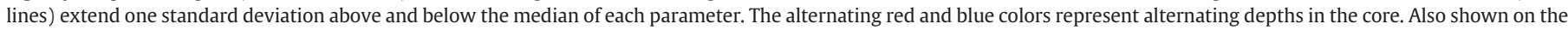

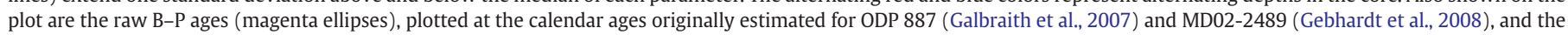
projection age (green line) calculated assuming a reservoir age correction of 900 years. The green star marks the estimated modern ventilation age at the core site. 
Results from core ODP 887 show a decrease in ventilation age during the deglacial transition. During the last glacial maximum (LGM) and early Heinrich I (H1), ventilation ages averaged about 1900 years, or about 400 years older than in the modern ocean. Ventilation ages dropped by approximately 600 years to near modern levels around the time of the Bølling-Ålerød (B-A) interval, and then fell below modern ventilation age values at the beginning of the Holocene. Despite the large uncertainty, the results generally support the conclusion of (Galbraith et al., 2007) that ventilation ages at this location were older during the LGM than in the Holocene, and that there is a significant decrease in ventilation age at around $15 \mathrm{ka}$. Our results also show a significant decrease in ventilation ages between 10 and $13 \mathrm{ka}$, when the ventilation age drops further by approximately 700 years.

The data from MD02-2489 are able to fill in some of the gaps in the record from ODP 887. LGM ventilation ages from core MD02-2489 generally agree with those from ODP 887 , but the higher-resolution record from MD02-2489 shows two large excursions in ventilation age, one near the beginning of $\mathrm{H} 1$ and one near the beginning of the $\mathrm{B}-\mathrm{A}$, that are not apparent from the ODP 887 record. Ventilation ages appear to drop to approximately 500 years near $17.5 \mathrm{ka}$, recover to near modern levels by $16-17 \mathrm{ka}$, and then increase to around 2500 years by $15 \mathrm{ka}$. Ventilation ages then drop back down to approximately 1300 years by $14.5 \mathrm{ka}$, consistent with the ventilation age estimates from ODP 887 for the B-A interval.

The two sediment-core records in combination imply some very large jumps in ventilation age over relatively short time spans. The results suggest that there was a drop in ventilation age of more than 1000 years at the beginning of the $\mathrm{H} 1$ interval in only a few hundred calendar years. Taken at face value, this rapid decrease in ventilation age might indicate a period when deep convection in the North Pacific penetrated to more than $3600 \mathrm{~m}$. For comparison, the modern ventilation age in the North Atlantic, a site of deep convection, is approximately 200-300 years (Matsumoto, 2007). Towards the end of the $\mathrm{H} 1$ interval, coming into the $\mathrm{B}-\mathrm{A}$, the results suggest an increase in ventilation age of more than 1000 years in only a few hundred calendar years, followed by a rapid decrease in ventilation age back to modern levels. This rapid transient increase in ventilation age could be explained by the influx of an old isolated water mass into the deep subarctic Pacific around $15 \mathrm{ka}$. This old water mass may have been flushed out of the deep ocean by approximately $14.5 \mathrm{ka}$ when ventilation ages return to modern levels.

Another important result from our analysis is that there is a large amount of uncertainty in the calendar ages and ventilation ages, as shown by the wide scatter of points representing the posterior pdf for each depth in the core. Some of the apparent large and rapid changes in ventilation age may in fact be less dramatic than they appear. For example, it is possible that the true calendar age for the points near 17$17.5 \mathrm{ka}$ lie toward the younger end of the estimated uncertainty. Since the calendar age and the ventilation age are anti-correlated, this would imply that the ventilation ages shift toward older values. Likewise, the very old ventilation age at around $15 \mathrm{ka}$ may in fact be younger if the true calendar age lies at the older end of its estimated uncertainty.

However, it should be noted that moving within the posterior pdf for the calendar age, $t$, and the ventilation age, $\theta$, also implies moving within the posterior pdf for other model parameters, since some of the model parameters are correlated with $t$ and $\Theta$. To demonstrate these correlations, Fig. 7 shows the joint posterior pdfs for $t$ (red dots) and $\Theta$ (blue dots) and the other model parameters. The plot shows results from the second depth in ODP 887, but similar relationships between the parameters occur at all depths in both cores.

Fig. 7 shows three clear correlations. First, the mean of the source region ETD, $\Theta_{e}^{s}$, is anti-correlated with the ventilation age, $\Theta$. This occurs because an older reservoir age in the source region implies a younger ventilation age, for a given deep ocean radiocarbon concentration. Second, the mean of the local surface ETD, $\Theta_{e}^{l}$, is tightly anti-correlated with the calendar age, $t$. This is because a younger local reservoir age implies an older calendar age, for a given surface ocean radiocarbon concentration. There are deviations from linearity in this relationship due to rapid variations in the atmospheric $\Delta^{14} \mathrm{C}$. The relationship also shows some scatter due to uncertainty in the measured planktonic age. Third, since both $\Theta_{e}^{l}$ and $\Theta$ are anti-correlated with $t, \Theta_{e}^{l}$ is positively correlated with $\theta$. The scatter plots do not show any correlations between either $t$ or $\theta$ and the width-controlling scale parameters ( $\beta e^{s}$, $\left.\beta e^{l}, \beta\right)$ for the ETDs and the TTD. This is reassuring, since it implies that the priors chosen for these parameters do not bias the inferred ventilation ages or calendar ages in any systematic way.
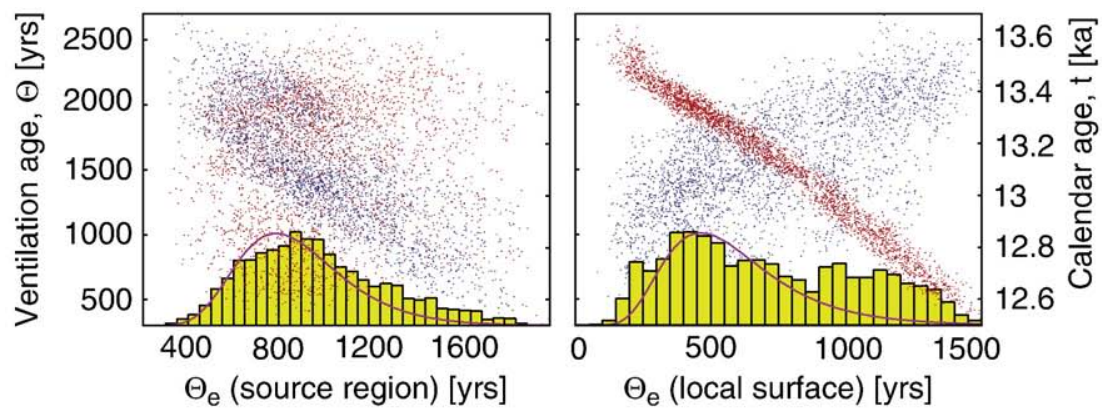

- Ventilation age (blue dots)

- Calendar age (red dots)

- Prior pdf

Posterior pdf
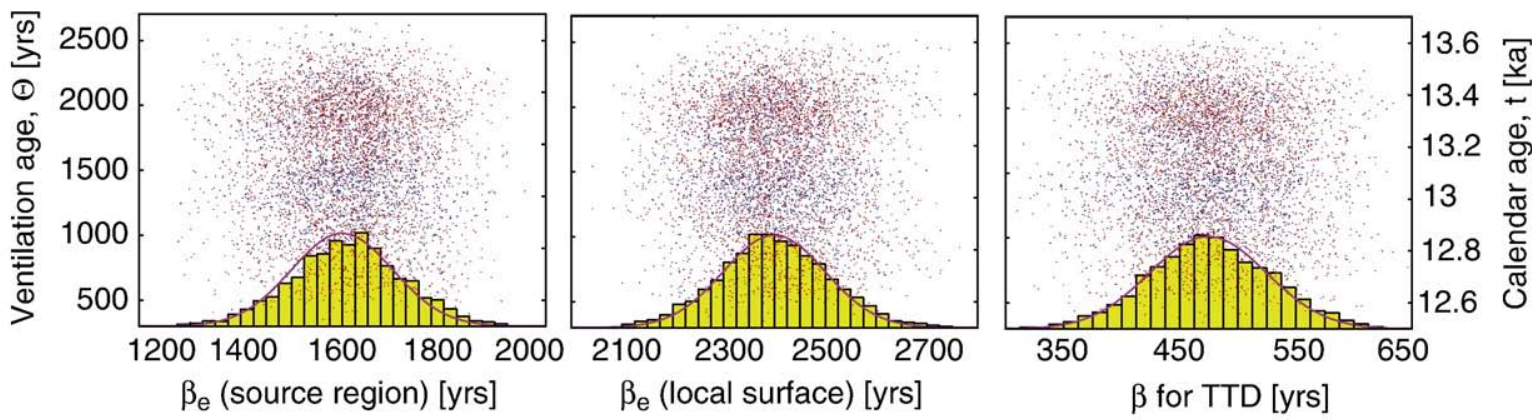

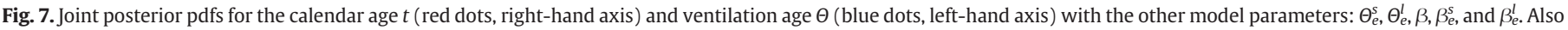

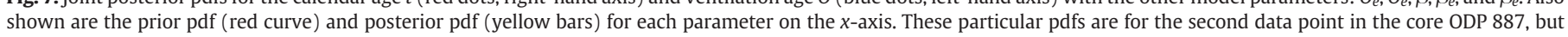
similar relationships are found at all depths in both cores. 
The additional constraints implied by the correlations in Fig. 7 suggest an alternative explanation for the rapid decrease in ventilation age shown at around $17.5 \mathrm{ka}$. Since the radiocarbon data provide little constraint on the mean equilibration time in the North Pacific, it is possible that the mean equilibration time (i.e. reservoir age) increased at this period, due perhaps to enhanced Ekman upwelling in the sub-polar gyre. An older mean equilibration time would push these particular points in the direction of younger calendar ages and older ventilation ages, according to the correlations shown in Fig. 7. This would bring these particular points more in line with the ventilation ages preceding and after this event. Similarly, the increase of ventilation age through the H1 interval seen in MD022489 would be consistent with decreased upwelling leading to a decline in the North Pacific surface reservoir age. This in turn would push the subsequent calendar ages toward older values and the ventilation ages toward younger values. If surface reservoir ages were very young at the end of $\mathrm{H} 1$, this would bring the very large ventilation age of 2500 years down so that it would be more in line with the preceding and subsequent ventilation ages.

While we have offered some possible interpretation for the inferred ventilation age changes over the last deglaciation in the North Pacific, the available radiocarbon data does not permit a definitive interpretation because not all the model parameters can be constrained independently. The large uncertainty should not be interpreted as a deficiency of the TTD-ETD parametric model, but rather a more accurate representation of our state of knowledge. In order to reduce the uncertainty in the inferred changes in ventilation ages it is particularly important to better constrain the mean of the ETDs for both the source region and the local surface water. This could be done with independently-dated radiocarbon ages for planktonic foraminifera from the North Pacific and the Southern Ocean during the last deglaciation. In the absence of such data, process studies using ocean general circulation models might be able to identify relationships between the mean of the TTD and ETD that could be used to better constrain these parameters.

\section{Conclusions}

In this paper we developed an improved method for inferring water mass ventilation ages from paired radiocarbon ages on benthic and planktonic foraminifera. The new method accounts for mixing processes in the ocean by using parameterized age distributions in integral equations that are solutions to the differential equation governing radiocarbon transport in the ocean. The method is coined the TTD-ETD method after the names (transit-time distribution and equilibration-time distribution) of the age distributions used in the method.

Ventilation ages predicted by the TTD-ETD method are significantly more accurate than either B-P ages or the projection ages. When applied to simulated radiocarbon data from an OGCM, the TTDETD method is able to closely reproduce the model-simulated ventilation ages in the deep North Pacific. Both the B-P age method and the projection method performed poorly in this region. The TTDETD method was also shown to be relatively insensitive to the choice of the width-controlling scale parameter for both the TTD and ETD, provided that the width does not approach zero, as is tacitly assumed for the projection method.

We also applied the TTD-ETD method to sediment-core radiocarbon data from two cores in the deep subarctic northeast Pacific, to re-assess ventilation ages across the last deglaciation in this region. For this purpose, we used a Bayesian probabilistic model to handle the uncertainty in both the radiocarbon data and in the assumptions we were forced to introduce in order to make the problem well-constrained.

The most robust conclusion from this analysis seems to be that the ventilation age of deep North Pacific water was higher in the LGM than in the modern ocean, which is supported by several data points from both cores. As well, ventilation ages appear to drop across the deglacial transition coming into the Bøllling-Ålerød and the Holocene. A few data points in one of the cores show some rapid changes in ventilation age during the Heinrich I interval. These results could also potentially signify large changes in the reservoir age of North Pacific surface waters during this time period.

As more independently-dated radiocarbon data becomes available, it will become possible to better constrain deep-ocean ventilation ages for the last glacial maximum and deglaciation. For this purpose, it will be important to use physically realistic models and to adequately treat all sources of uncertainty. The TTD-ETD method presented here, along with the Bayesian probabilistic model for handling uncertainties, fits both of these requirements.

\section{Acknowledgements}

The authors would like to thank Mark Holzer, Eric Galbraith, and two anonymous reviewers for insightful comments that helped to improve the quality of the manuscript. We would also like to thank John Southon for help with interpreting radiocarbon data and for stimulating discussions. This research used samples and/or data provided by the Ocean Drilling Program (ODP). ODP is sponsored by the U.S. National Science Foundation (NSF) and participating countries under management of Joint Oceanographic Institutions (JOI), Inc. Funding for this research was provided by NSF grant OCE-0726871.

\section{Appendix A. Formulation of the Green functions $\mathcal{G}$ and $\mathcal{K}$}

In this appendix we present the equations that govern and define the Green functions $\mathcal{G}\left(t, \mathbf{r} \mid \mathbf{r}_{s}, t-\tau\right)$ and $\mathcal{K}\left(t-\tau, \mathbf{r}_{s} \mid t-\tau-\tau_{e}\right)$. To reduce notational clutter, we will introduce the substitutions $t^{\prime}=t-\tau$ and $t^{\prime \prime}=t-\tau-\tau_{e}$. We will show how the Green functions can be obtained from both the forward and adjoint tracer transport equations.

\section{Appendix A.1. Forward equations}

For the special case of time-independent flow, the Green functions can be found as particular solutions of the general differential equation for radiocarbon (1). The transit-time distribution can be found by solving

$\frac{\partial}{\partial t} \mathcal{G}\left(t, \mathbf{r} \mid \mathbf{r}_{s}, t^{\prime}\right)+\nabla \cdot[\mathbf{u}-\mathbf{K} \cdot \nabla] \mathcal{G}\left(t, r \mid r_{s}, t^{\prime}\right)=0$

subject to the boundary condition

$\mathcal{G}\left(t, \mathbf{r} \mid \mathbf{r}_{s}, t^{\prime}\right)=\delta^{2}\left(\mathbf{r}-\mathbf{r}_{s}\right) \delta\left(t^{\prime}\right)$

at the ocean surface and to a no-flux boundary condition on all other boundaries, and subject to the initial condition

$\mathcal{G}\left(t, \mathbf{r} \mid \mathbf{r}_{s}, t^{\prime}\right)=0$

for $t<t^{\prime}$

The equilibration-time distribution can be found by solving the differential equation

$\frac{\partial}{\partial t} \mathcal{K}\left(t^{\prime}, \mathbf{r}_{s} \mid t^{\prime \prime}\right)+\nabla \cdot[\mathbf{u}-\mathbf{K} \cdot \nabla] \mathcal{K}\left(t^{\prime}, \mathbf{r}_{s} \mid t^{\prime \prime}\right)=0$

subject to a surface boundary condition where the air-sea flux is given by

$F=k\left[\delta\left(t^{\prime \prime}\right)-K\left(t^{\prime}, \mathbf{r}_{s} \mid t^{\prime \prime}\right)\right]$

and to a no-flux boundary condition on all other boundaries. 
The gas transfer velocity $k$ for radiocarbon can be computed from the governing equation for the air-sea equilibration of ${ }^{14} \mathrm{C}$ as described in Appendix B.

\section{Appendix A.2. Adjoint equations}

For the case of time-dependent flow, the Green functions can be found as particular solutions of the adjoint of the general differential equation for radiocarbon (1). The transit-time distribution for timedependent flow can be found by first solving the adjoint equation

$-\frac{\partial}{\partial t^{\prime}} \tilde{G}\left(t^{\prime}, \mathbf{r} \mid t, \mathbf{r}^{\prime}\right)-\nabla \cdot\left[\mathbf{u}+\mathbf{K}^{\mathbf{T}} \cdot \nabla\right] \tilde{G}\left(t^{\prime}, \mathbf{r} \mid t, \mathbf{r}^{\prime}\right)=\delta^{3}\left(\mathbf{r}^{\prime}-\mathbf{r}\right) \delta\left(t-t^{\prime}\right)$

where $\mathbf{r}^{\prime}$ is the set of all points in the interior ocean. Eq. (A.6) is solved subject to a boundary condition of zero tracer at the surface and a noflux condition at all other boundaries, and with the causality condition $t^{\prime} \leq t$ so that time runs backwards (Holzer and Hall, 2000). The TTD is then given by (Holzer and Hall, 2000)

$\mathcal{G}\left(t, \mathbf{r} \mid \mathbf{r}_{s}, t^{\prime}\right)=\hat{\mathbf{n}} \cdot \mathbf{K}^{\mathbf{T}} \nabla \tilde{G}\left(t^{\prime}, \mathbf{r} \mid t, \mathbf{r}^{\prime}\right)$

where $\hat{\mathbf{n}}$ is a vector normal to the ocean surface with length one at $\mathbf{r}_{s}$ and zero elsewhere.

The equilibration-time distribution for time-dependent flow can be found by first solving the adjoint equation

$-\frac{\partial}{\partial t^{\prime \prime}} \tilde{K}\left(t^{\prime \prime}, \mathbf{r} \mid t^{\prime}, \mathbf{r}_{s}\right)-\nabla \cdot\left[\mathbf{u}+\mathbf{K}^{\mathbf{T}} \cdot \nabla\right] \tilde{K}\left(t^{\prime \prime}, \mathbf{r} \mid t^{\prime}, \mathbf{r}_{s}\right)=\delta^{3}\left(\mathbf{r}-\mathbf{r}_{s}\right) \delta\left(t^{\prime}-t^{\prime \prime}\right)$.

Eq. (A.8) is solved with the causality condition $t^{\prime \prime} \leq t^{\prime}$, and subject to a no-flux boundary condition on all boundaries except the seasurface where the air-sea flux is given by

$F=-k\left(t^{\prime \prime}, \mathbf{r}_{s}\right) \tilde{K}\left(t^{\prime \prime}, r \mid t^{\prime}, r_{s}\right)$

Given $\tilde{\mathrm{K}}$, the ETD is obtained from

$\mathcal{K}\left(t^{\prime}, \mathbf{r}_{s} \mid t^{\prime \prime}\right)=\frac{\partial}{\partial t^{\prime \prime}} \int_{V} \tilde{K}\left(t^{\prime \prime}, \mathbf{r} \mid t^{\prime}, \mathbf{r}_{s}\right) d \mathbf{r}$

\section{Appendix B. The gas transfer velocity for radiocarbon}

The differential equation for the transfer of ${ }^{14} \mathrm{C}$ between the atmosphere and the ocean can be written

$$
\frac{d^{14} \mathrm{C}}{d t}=\frac{K_{w}}{d_{m l}} s \Delta p^{14} \mathrm{CO}_{2}
$$

where $K_{w}$ is the $\mathrm{CO}_{2}$ gas transfer velocity [m/yr], $d_{m l}$ is the depth of the surface mixed layer $[\mathrm{m}], s$ is the solubility of $\mathrm{CO}_{2}$ in seawater $\left[\mathrm{mol} / \mathrm{m}^{3} /\right.$ atm], $\mathrm{C}$ is the dissolved inorganic carbon (DIC) concentration in seawater $\left[\mathrm{mol} / \mathrm{m}^{3}\right]$, and $\Delta p^{14} \mathrm{CO}_{2}$ is the air-sea gradient in the partial pressure of ${ }^{14} \mathrm{CO}_{2}$ (Sweeney et al., 2007)

$\Delta p^{14} \mathrm{CO}_{2}=\alpha_{k} \alpha_{a q-g}\left[\frac{{ }^{14} \mathrm{C}_{a t m}}{{ }^{12} \mathrm{C}_{a t m}} p \mathrm{CO}_{2}^{a t m}-\frac{{ }^{14} \mathrm{C}}{{ }^{12} \mathrm{C} \alpha_{C-g}} p \mathrm{CO}_{2}^{o c e}\right]$.

The isotopic fractionation factors $\alpha_{k}, \alpha_{a q-g}$, and $\alpha_{C-\mathrm{g}}$ may be ignored in radiocarbon simulations since reported radiocarbon data are corrected for isotopic fractionations effects (Toggweiler et al.,
1989). The normalized ratio of carbon-14 to carbon-12 atoms is given by the $R$ value

$R=\frac{{ }^{14} \mathrm{C} /{ }^{12} \mathrm{C}}{R_{\text {standard }}}$

Combining Eqs. (B.1)-(B.3) and ignoring the fractionation factors yields

$\frac{d}{d t}\left(R^{12} \mathrm{C}\right)=\frac{K_{w}}{d_{m l}} S\left[R_{a t m} p \mathrm{CO}_{2}^{a t m}-R p \mathrm{CO}_{2}^{o c e}\right]$.

This can be re-arranged to yield a differential equation for $R$,

$\frac{d R}{d t}=\frac{K_{w}}{d_{m l}} s \frac{p \mathrm{CO}_{2}^{a t m}}{{ }^{12} \mathrm{C}} R_{a t m}-\left[\frac{K_{w}}{d_{m l}} s \frac{p \mathrm{CO}_{2}^{o c e}}{{ }^{12} \mathrm{C}}+\frac{1}{{ }^{12} \mathrm{C}} \frac{d^{12} \mathrm{C}}{d t}\right] R$.

To a first approximation we can consider ${ }^{12} \mathrm{C}$ a constant equal to the global average surface DIC concentration $\overline{\mathrm{DIC}}$, and $p \mathrm{CO}_{2}^{\text {oce }}$ can be set equal to $\mathrm{pCO}_{2}^{\text {atm }}$ (Butzin et al., 2005). Using these approximations in Eq. (B.5) yields

$\frac{d R}{d t}=\frac{k}{d_{m l}}\left(R_{a t m}-R\right)$

where the gas exchange piston velocity $k$ is given by

$k=K_{w} s \frac{p \mathrm{CO}_{2}^{a t m}}{\overline{\mathrm{DIC}}}$

\section{References}

Adkins, J.F., Boyle, E.A., 1997. Changing atmospheric $\Delta^{14} \mathrm{C}$ and the record of deep water paleoventilation ages. Paleoceanography 12 (3), 337-344.

Broecker, W., Barker, S., Clark, E., Hajdas, I., Bonani, G., Stott, L., 2004. Ventilation of the Glacial Deep Pacific Ocean. Science 306, 1169-1172.

Broecker, W., Clark, E., Barker, S., 2008. Near constancy of the Pacific Ocean surface to mid-depth radiocarbon-age difference over the last $20 \mathrm{kyr}$. Earth Planet. Sci. Lett. 274, 322-326.

Brooks, S.P., Gelman, A., 1998. General methods for monitoring convergence of iterative simulations. J. Comput. Graph. Stat. 7 (4), 434-455.

Butzin, M., Prange, M., Lohmann, G., 2005. Radiocarbon simulations for the glacial ocean: the effects of wind stress, Southern Ocean sea ice and Heinrich events. Earth Planet. Sci. Lett. 235, 45-61.

Delhez, E., Campin, J.-M., Hirst, A., Deleersnijder, E., 1999. Toward a general theory of the age in ocean modelling. Ocean Model. 1, 17-27.

Delhez, E., Deleersnijder, E., Mouchet, A., Beckers, J.-M., 2003. A note on the age of radioactive tracers. J. Mar. Syst. 38, 277-286.

Feely, R.A., Sabine, C.L., Schlitzer, R., Bullister, J.L., Mecking, S., Greeley, D., 2004. Oxygen utilization and organic carbon remineralization in the upper water column of the Pacific Ocean. J. Oceanogr. 60, 45-52.

Fiadeiro, M.E., 1982. Three-dimensional modeling of tracers in the deep Pacific Ocean, II. Radiocarbon and the circulation. J. Mar. Res. 40, 537-550.

Franke, J., Paul, A., Schulz, M., 2008a. Modeling variations of marine reservoir ages during the last 45000 years. Climate Past 4, 125-136.

Franke, J., Schulz, M., Paul, A., Adkins, J.F., 2008b. Assessing the ability of the ${ }^{14} \mathrm{C}$ projection-age method to constrain the circulation of the past in a 3-D ocean model. Geochem. Geophys. Geosyst. 9 (8). doi:10.1029/2008GC001943.

Galbraith, E.D., Jaccard, S.L., Pedersen, T.F., Sigman, D.M., Haug, G.H., Cook, M., Southon, J.R., Francois, R., 2007. Carbon dioxide release from the North Pacific abyss during the last deglaciation. Nature 449, 890-894.

Gebbie, G., Huybers, P., in press. Total matrix intercomparison: a method for determining the geometry of water-mass pathways. Journal of Physical Oceanography, doi:10.1175/2010JPO4272.1.

Gebhardt, H., Sarnthein, M., Grootes, P.M., Kiefer, T., Kuehn, H., Schmieder, F, Röhl, U, 2008. Paleonutrient and productivity records from the subarctic North Pacific for Pleistocene glacial terminations I to V. Paleoceanography 23, PA4212. doi:10.1029/ 2007PA001513.

Haine, T.W.N., 2006. On tracer boundary conditions for geophysical reservoirs: how to find the boundary concentration from a mixed condition. J. Geophys. Res. 111, C05003. doi:10.1029/2005JC003215.

Haine, T.W.N., Hall, T.M., 2002. A generalized transport theory: water-mass composition and age. J. Phys. Oceanogr. 32, 1932-1946.

Hall, T.M., Haine, T.W., Waugh, D.W., 2002. Inferring the concentration of anthropogenic carbon in the ocean from tracers. Global Biogeochem. Cycles 16. doi:10.1029/ 2001 GB001835. 
Hall, T.M., Haine, T.W.N., Holzer, M., LeBel, D.A., Terenzi, F., Waugh, D.W., 2007. Ventilation rates estimated from tracers in the presence of mixing. J. Phys. Oceanogr. 37. doi:10.1175/2006JPO3471.1.

Hall, T.M., Waugh, D.W., Haine, T.W., Robbins, P.E., Khatiwala, S., 2004. Estimates of anthropogenic carbon in the Indian Ocean with allowance for mixing and air-sea $\mathrm{CO}_{2}$ disequilibrium. Global Biogeochem. Cycles. doi:10.1029/2003GB002120.

Hastings, W.K., 1970. Monte Carlo sampling methods using Markov chains and their applications. Biometrika 57 (1), 97-109.

Holzer, M., Hall, T.M., 2000. Transit-time and tracer-age distributions in geophysical flows. J. Atmos. Sci. 57, 3539-3558.

Holzer, M., Primeau, F.W., 2008. The path-density distribution of oceanic surface-tosurface transport. J. Geophys. Res. 113 (C), C01018.

Holzer, M., Primeau, F. W., Smethie, W. M., Khatiwala, S., in press. Where and how long ago was water in the western north Atlantic ventilated? Maximum entropy inversions of bottle data from WOCE line A20. Journal of Geophysical Research Oceans. doi:10.1029/2009JC005750.

Key, R.M., Kozyr, A., Sabine, C.L., Lee, K., Wanninkhof, R., Bullister, J.L., Feely, R.A., Millero, F.J., Mordy, C., Peng, T.-H., 2004. A global ocean carbon climatology: results from Global Data Analysis Project (GLODAP). Global Biogeochem. Cycles 18, GB4031. doi:10.1029/2004GB002247.

Khatiwala, S., Primeau, F., Hall, T., 2009. Reconstruction of the history of anthropogenic $\mathrm{CO}_{2}$ concentrations in the ocean. Nature 462, 346-349.

Kovanen, D.J., Easterbrook, D.J., 2002. Paleodeviations of radiocarbon marine reservoir values for the northeast Pacific. Geology 30, 243-246.

Marchitto, T.M., Lehman, S.J., Ortiz, J.D., Flückiger, J., van Geen, A., 2007. Marine radiocarbon evidence for the mechanism of deglacial atmospheric $\mathrm{CO}_{2}$ rise. Science 316 (5830), 1456-1459.

Matsumoto, K., 2007. Radiocarbon-based circulation age of the world oceans. J. Geophys. Res. 112 (C3).

Peacock, S., Maltrud, M., 2006. Transit-time distributions in a global ocean model. J. Phys. Oceanogr. 36 (3), 474-495.

Primeau, F., Holzer, M., 2006. The ocean's memory of the atmosphere: residence-time and ventilation-rate distributions of water masses. J. Phys. Oceanogr. 36, 1439-1456.
Primeau, F.W., 2005. Characterizing transport between the surface mixed layer and the ocean interior with a forward and adjoint global ocean transport model. J. Phys. Oceanogr. doi:10.1175/JPO2699.

Reimer, P.J., Baillie, M.G.L., Bard, E., Bayliss, A., Beck, J.W., Blackwell, P.G., Bronk Ramsey, C., Buck, C.E., Burr, G.S., Edwards, R.L., Friedrich, M., Grootes, P.M., Guilderson, T.P., Hajdas, I., Heaton, T.J., Hogg, A.G., Hughen, K.A., Kaiser, K.F., Kromer, B., McCormac, F.G., Manning, S.W., Reimer, R.W., Richards, D.A., Southon, J.R., Talamo, S., Turney, C.S.M., van der Plicht, J., Weyhenmeyer, C.E., 2009. IntCal09 and Marine09 radiocarbon age calibration curves, 0-50,000 years cal BP. Radiocarbon 51 (4), 1111-1150.

Robinson, L.F., Adkins, J.F., Keigwin, L.D., Southon, J., Fernandez, D.P., Wang, S.-L., Scheirer, D.S., 2005. Radiocarbon variability in the Western North Atlantic during the last deglaciation. Science 310, 1469-1473.

Rodgers, K.B., Schrag, D.P., Cane, M.A., Naik, N.H., 2000. The bomb ${ }^{14} \mathrm{C}$ transient in the Pacific Ocean. J. Geophys. Res. 105 (C4), 8489-8512.

Sikes, E.L., Samson, C.R., Guilderson, T.P., Howard, W.R., 2000. Old radiocarbon ages in the southwest Pacific Ocean during the last glacial maximum. Nature 405, 555-559.

Southon, J.R., Nelson, D.E., Vogel, J.S., 1990. A record of past ocean-atmosphere radiocarbon differences from the northeast Pacific. Paleoceanography 5, 197-206.

Sivia, D.S., Skilling, J., 2006. Data Analysis: A Bayesian Tutorial. Oxford University Press.

Sweeney, C., Gloor, E., Jacobson, A.R., Key, R.M., McKinley, G., Sarmiento, J.L., Wanninkhof, R., 2007. Constraining global air-sea gas exchange for $\mathrm{CO}_{2}$ with recent bomb ${ }^{14} \mathrm{C}$ measurements. Global Biogeochem. Cycles 21.

Thiele, G., Sarmiento, J.L., 1990. Tracer dating and ocean ventilation. J. Geophys. Res. 95 (C6), 9377-9391.

Toggweiler, J.R., Dixon, K., Bryan, K., 1989. Simulations in a coarse-resolution world ocean model, I. Steady state prebomb distributions. J. Geophys. Res. 8217-8242.

Waugh, D.W., Hall, T.M., Haine, T.W., 2003. Relationships among tracer ages. J. Geophys. Res. 108. doi:10.1029/2002JC001325.

Waugh, D.W., Hall, T.M., McNeil, B.I., Key, R., 2006. Anthropogenic $\mathrm{CO}_{2}$ in the oceans estimates using transit-time distributions. Tellus 58B, 376-389. 